\title{
АНАЛИЗ ПРОЦЕССОВ ПОДГОТОВКИ ПРОИЗВОДСТВА МЕЛКОСЕРИЙНЫХ ПРОИЗВОДСТВЕННЫХ ПРЕДПРИЯТИЙ
}

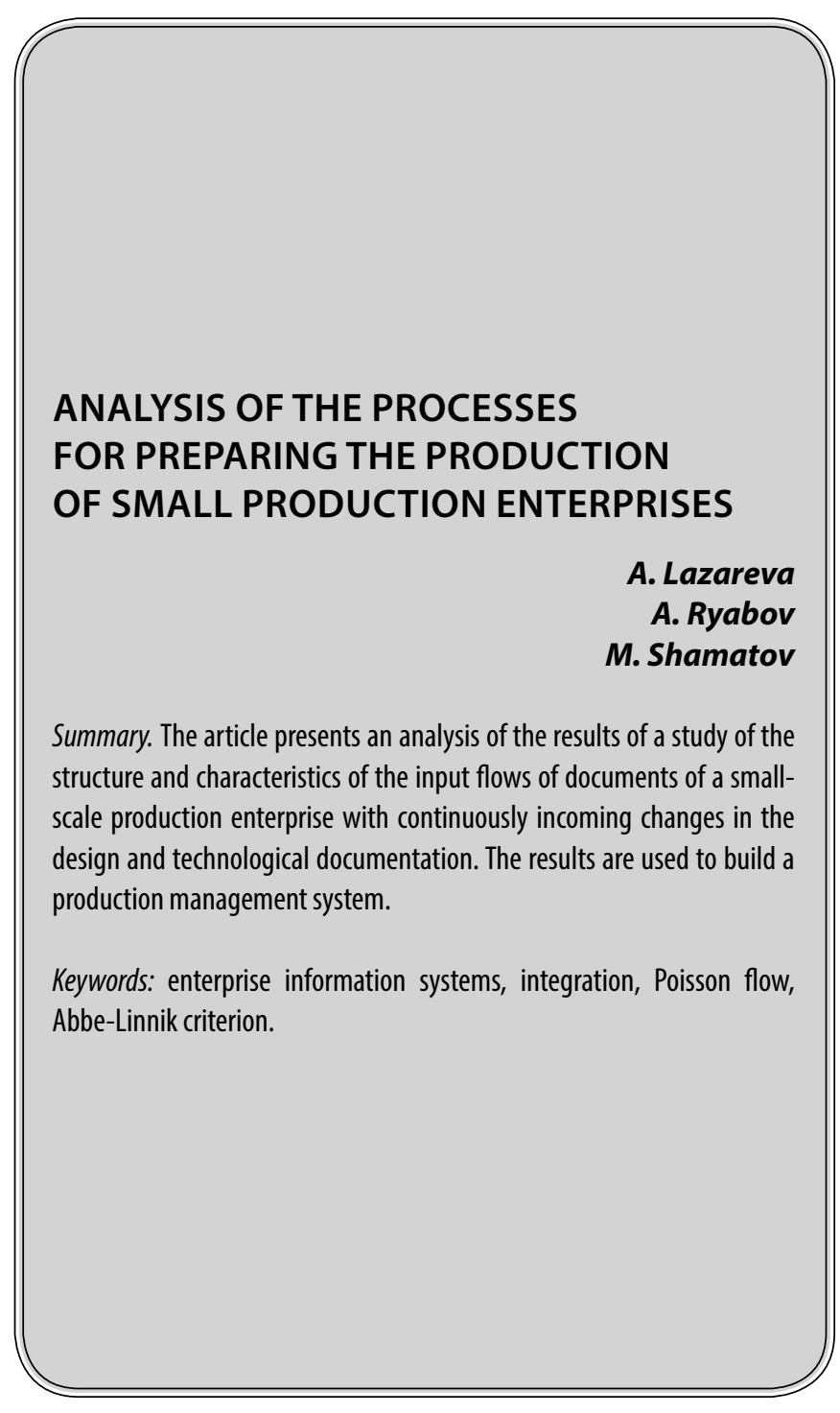

B сокращении сроков и затрат на разработку и выпуск мелкосерийной продукции важной составляющей является скорость проведения изменений конструкторской документации. Выделяют три основных причины частых изменений:

- модификация изделий;

- замены комплектующих материалов;

- длительность проведения закупочных процедур.

Следовательно, важно обеспечить надежное управление всем объемом конструкторской документации, которая создается, хранятся и используются в различных информационных системах предприятия.
Лазарева Антонина Борисовна К.т.н., дочент, Арзамасский политехнический институт (филиал) ФГБОУ ВО «Нижегородский государственный технический университет

им. Р.Е. Алексеева»

lazareva@apingtu.edu.ru

Рябов Антон Владимирович

К.т.н., дочент, Арзамасский политехнический институт (филиал) ФГБОУ ВО «Нижегородский государственный технический университет

им. Р.Е. Алексеева»

Шаматов Максим Вячеславович

Арзамасский политехнический институт (филиал) ФГБОУ ВО «Нижегородский государственный технический университет им. Р.Е. Алексеева»

Аннотация. В статье представлен анализ результатов исследования структуры и характеристик входных потоков документов мелкосерийного производственного предприятия при непрерывно поступающих изменениях в конструкторской и технологической документациях. Приведенные результаты использованы при построении системы управления производством.

Ключевые слова: информационные системы предприятия, интеграция, пуассоновский поток, критерий Аббе-Линника.

В [1] предлагается сопряжение двух российских информационных систем: PDM-системы «T-Flex Docs» и ERP-системы «1С: Управление производственным предприятием» (рисунок 1).

Для создания модуля программной интеграции между системами «T-Flex Docs» и «1C: Управление производственным предприятием», необходимо, прежде всего, выполнить статистический анализ входных потоков данных.

Был выполнен сбор статистических данных об изменениях входных потоков документов. Доказано, что 
Таблица 1.

\begin{tabular}{|c|c|c|c|c|c|c|c|c|c|c|c|c|}
\hline 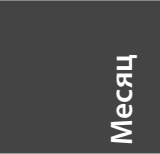 & 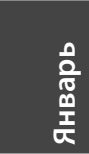 & 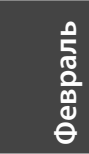 & $\frac{\mathfrak{b}}{\frac{0}{10}}$ & $\begin{array}{l}\text { 紊 } \\
\text { 은 } \\
\text { 운 }\end{array}$ & $\sum^{105}$ & $\begin{array}{l}\text { 궁 } \\
\text { 온 }\end{array}$ & 호 & $\begin{array}{l}5 \\
\frac{5}{2} \\
\text { 商 }\end{array}$ & 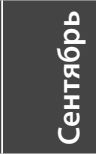 & 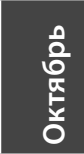 & $\begin{array}{l}\text { 응 } \\
\text { 응 } \\
\text { 온 }\end{array}$ & $\begin{array}{l}\text { 옹 } \\
0 \\
\frac{0}{0}\end{array}$ \\
\hline $\begin{array}{l}\text { Число } \\
\text { изменений }\end{array}$ & 319 & 269 & 307 & 227 & 275 & 267 & 195 & 254 & 273 & 294 & 294 & 300 \\
\hline
\end{tabular}

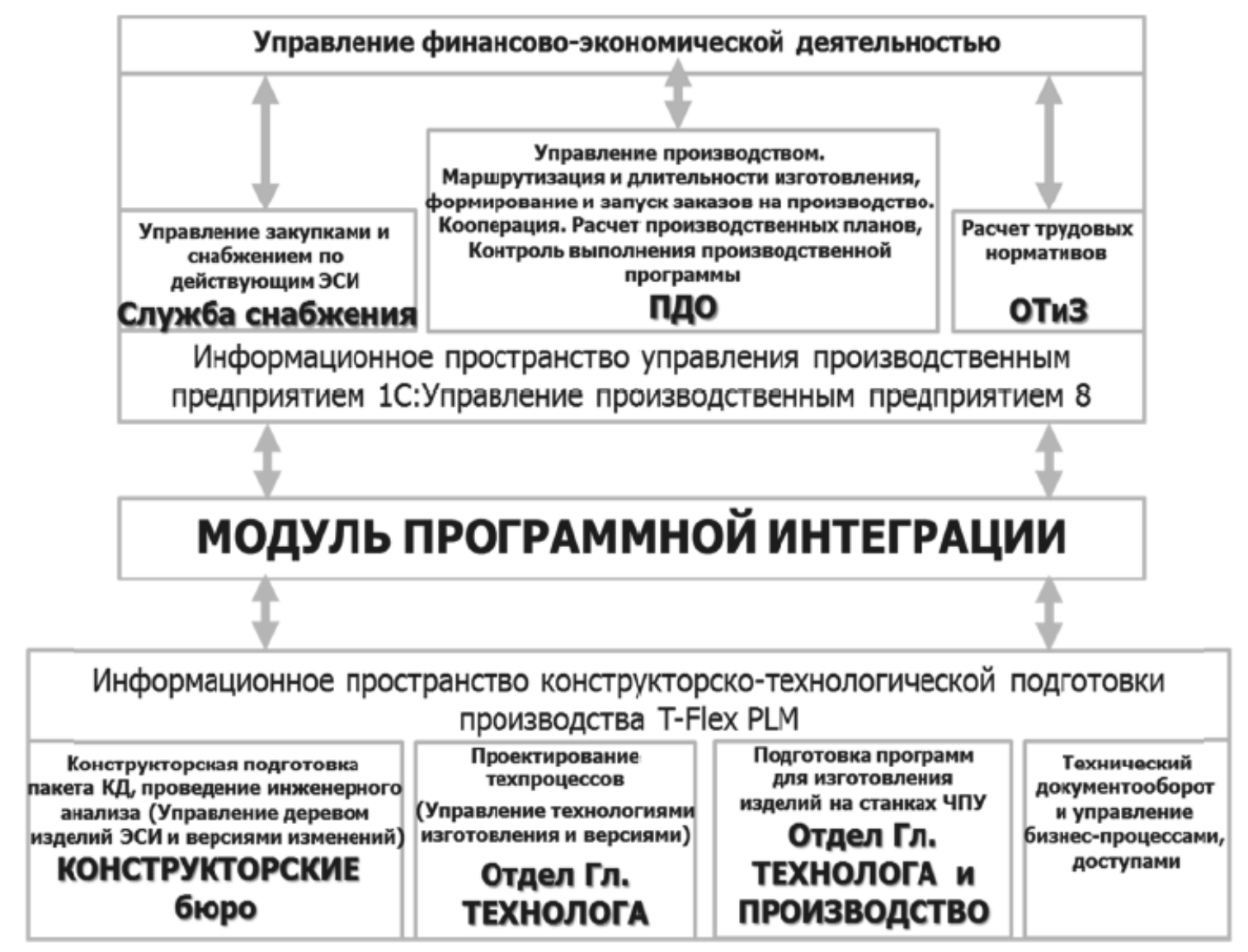

Рис. 1.

поток является пуассоновским, т.е. он обладает тремя свойствами [2]: стационарность, ординарность, отсутствие последействия.

Стационарность характеризуется независимостью плотности вероятности от начала отсчета времени. То есть, если взять на временной оси $n$ непересекающихся интервалов длиной $\Delta_{i}, i=\overline{1, n}$. Обозначим $\eta_{i}$ число событий, приходящихся на интервал $\Delta_{i}$. Тогда

$$
P\left\{\eta_{i}=k\right\}, k \geq 0, i=\overline{1, n} \text {. }
$$

Поток входных документов, в которых были выполнены изменения, анализировался в течение трех лет.
В таблице 1 представлен анализируемый ряд изменений в потоках документов за год.

Для установления закона распределения входного потока документов строилась гистограмма [5]. Это инструмент, который позволяет оценить распределение статистических данных, сгруппированных по частоте попадания данных в некоторые заранее установленные интервалы. Проверка гипотезы нормальности распределения по критерию согласия Колмогорова позволила сделать вывод о том, что эмпирическое распределение входного потока документов подчиняется нормальному закону. Это позволяет использовать для анализа стационарности использовать критерий Аббе-Линника [4]. 


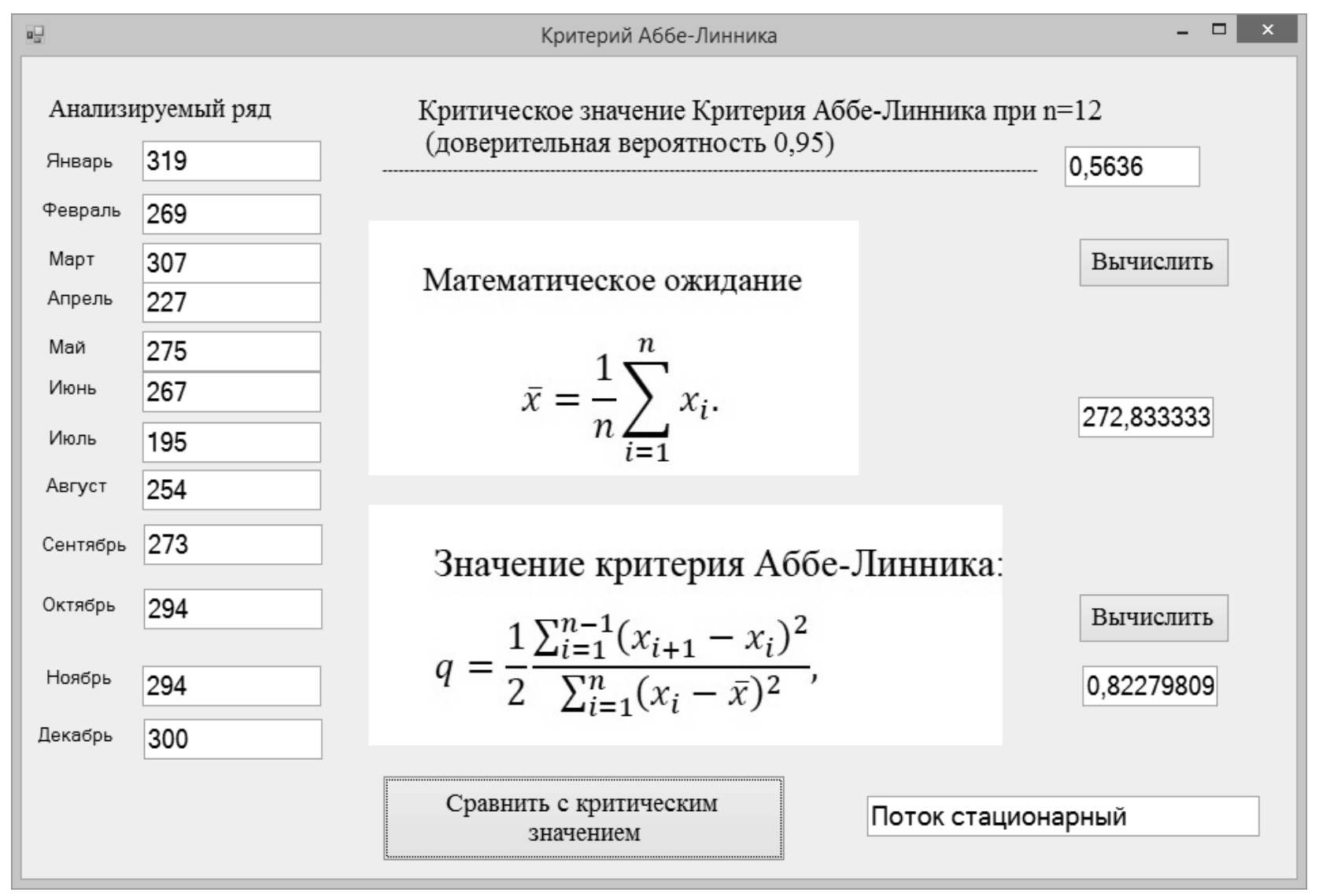

Рис. 2.

Проверяется нулевая гипотеза о том, что все выборочные значения принадлежат одной генеральной совокупности со средним

$$
\mu:\left(H_{0}: \mu_{i}=\mu, i=1,2, \ldots, n\right) .
$$

Статистика критерия Аббе-Линника имеет вид:

$$
\begin{aligned}
& q=\frac{1}{2} \frac{\sum_{i=1}^{n-1}\left(x_{i+1}-x_{i}\right)^{2}}{\sum_{i=1}^{n}\left(x_{i}-\bar{x}\right)^{2}}, \\
& \bar{x}=\frac{1}{n} \sum_{i=1}^{n} x_{i} .
\end{aligned}
$$

Если $q>q_{\sigma}$ то нулевая гипотеза случайности ряда $x_{1}, \ldots, x_{n}$ отклоняется с доверительной вероятностью $\alpha$ (доверительная вероятность а и критические значения $q_{\sigma}$ критерия Аббе-Линника приведены в таблице [3]).

Для выполнения расчетов в среде программирования Visual C++ создано приложение Widows Forms.

На рисунке 2 представлена форма для анализа стационарности изменений в потоках документов за год (таблица 1).
Вычисленное значение критерия Аббе-Линника $q=$ 0,822798. $q>q_{6}$, следовательно, можно сделать вывод о стационарности потока, то есть ежемесячно он в течение года меняется незначительно.

В [6] приведено определение потока без последствия. Смысл этого определения заключается в том, что наступление событий на каком-то интервале не зависит от того, сколько событий появилось на других интервалах. В исследуемом потоке последействие отсутствует.

Ординарность предполагает бесконечно малую вероятность поступления более одного события за бесконечно малый отрезок времени. Это свойство присуще потоку рассматриваемых документов, так как вероятность поступления более одного документа в один момент времени очень мала.

Для реализации двустороннего обмена конструкторско-технологической информацией между двумя системами используется общую промежуточную базу данных на основе СУБД MS SQL Server [7]. В PDМ-системе выполняется разработка и согласование, а в ERP-системе запуск изделий в производство, последующая поддержка и аннулирование. 


\section{ЛИТЕРАТУРА}

1. Жилина, С. Б. Автоматизация процесса информационного обеспечения производства приборостроительного предприятия комплектующими изделиями// Известия Самарского научного центра Российской академии наук. — 2016. — т. 18, № 4(7). — C. 1372-1380.

2. Назаров А.А., Терпугов А. Ф. Теория массового обслуживания: учебное пособие.— 2-е изд., испр. — Томск: Изд-во НТJ. 2010 .-228 с.

3. Большев Л.Н., Смирнов Н. В. Таблицы математической статистики — М.: Наука. Главная редакция физико-математической литературы, 1983. - 416 c.

4. Линник Ю. В. Метод наименьших квадратов и основы математико-статистической теории обработки наблюдений. М.: Физматлит, 1958. 336 с.

5. Лазарева А.Б., Эварт Т. Е., Глухова А. Ф. Объектно-ориентированное программирование. Использование Windows Forms при решении инженерных задач: учеб. пособие - Нижегород. гос.тех. ун-т им. Р.Е. Алексеева.—Нижний Новгород, 2017.—94 с.

6. Кингман Дж. Пуассоновские процессы.- М.: МЦНМ0, 2007.- 136 с.

7. Роберт Э. Уолтерс, Майкл Коулс. SQL Server 2008: ускоренный курс для профессионалов = Accelerated SQL Server 2008.— М.: «ВильямС», 2008.—C. 768.

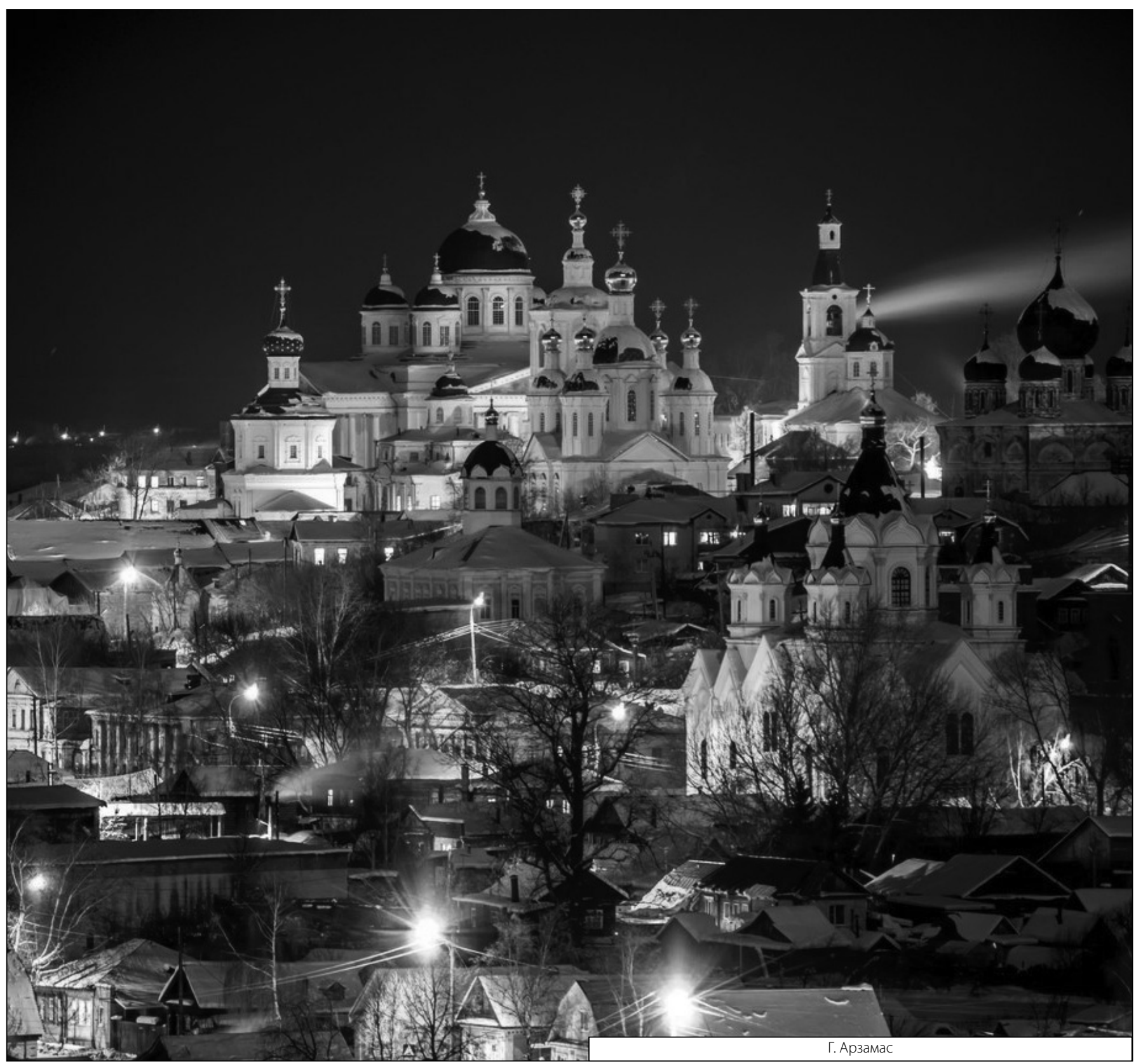

